Zähler ist 20 Thlr., mit deuselben 32 Thlr.; der mit einem gewöhulichen Strom 25 Thlr.

XIII. Ueber eine merkwürdige Blitz-Erscheinung; con Hrn. .J. P. Joule in Manchester ${ }^{1}$ ).

\begin{abstract}
Am 16. Juli d. J. (1850) un 4 Uhr Nachınittags, nach einem sehr schwülen Morgen, wurde unsere Stadt und Umgebung von einem Gewitter mit heftigem Regen heimgesucht. Am Abend desselben Tages, um 9 Uhr, hatten wir das Schauspiel höchst prachtvoller elektrischer Entladungen, welche unausgesetzt fast eine Stunde lang anhielten, aber nur von wenig Regentropfen begleitet waren. Niemals habe ich Blitze von so aufserordentlichem Charakter gesehen. Jede Entladung schien von einer Wolkenmasse in Südwesten auszugehen und durchlief in Richtung des Beobachters eine Strecke von 6 bis 10 engl. Meilen; dabei theilten sich die Blitze in ein halbes Dutzend und mehr Fuuken oder zickzackförmiger Lichtstreifen, die zuweilen an ihren Enden wiederum in eine Anzahl kleinerer Funken zerstiebten, wie es in Fig. 7 Taf. II. angegeben ist. Ich konnte nicht beobachten, dals irgend eine dieser Entladungen den Erdboden erreichte; und aus der Zeit, die zwischen dem Erscheinen der das Zenit durchkreuzenden Blitze und dem Donner verstrich, glaube ich ihre Höhc über der Erde durchschuittlich auf wenigstens $3_{\frac{1}{2}}^{\frac{1}{2}}$ engl. Meilen veranschlagen zu müssen.

Die divergirende Form entsprang ohne $\mathrm{Zweifel}$ aus der ausgedehnten negativen Oberfläche der Wolken; sie lälst sich in kleinem Maalsstabe nachahmen, wenn man cine Glasflasche mit Wasser füllt und als Leidner Flasche ge1) Aus den Phil. Mrgaz. Vol. XXXVII, p. 127.
\end{abstract}


- braucht. Weun man eine solche Flasche dergestalt entladet, dafs man den einen Knopf des Entladers an die ăufsere Glasfläche, den audern auf die Wasserfläche setzt, so divergirt der elektrische Funke über die ganze Glasoberfläche (glass surface).

Ein anderer merkwürdiger Umstand bei jenen Blitzen war die merkliche Zeit ihres Laufes gegen den Beobachter. Die Haupt-Lichtstreifen waren immer erst gebildet, bevor die Funken divergirten; und nachdem sie gebildet worden, blieben sic eine wahruehmbare Zeit stehen, bis das Ganze verschwand. Meine Brüder, Benjamin und John, welche die Blitze zwei (engl.) Meilen westlich von meinem Standpunkt beobachteten, saheu sie genau von gleichem Charakter; überdiefs war der Letztere, nebst mehren andereu Personen, Zeuge eines Phänomens, welches ich dem elektrischen Zustand der Atmosphäre zuschreibe und meines Wissens noch nicht beschrieben worden.

Um 8: Ubr erschien unter deu Wolken, die fast genau im Südeu und etwa $30^{\circ}$ über dem Horizonte standen, ein helles rothes Licht; es schien als wenu die Soune hinter einer Wolke stände und deren Ränder stark erleuchtete; es warf auf die benachbarten Wolken cin glänzendes Licht. Es dauterte mil voller Beständigkeit ctwa fünf Minuten und verschwand daun allmälig.

\section{Merkwürdiges Wind-Phänomen.}

Kapitain Bonnet, Commandant des Schiffes Le Lion, erlebte vurigen Jahres auf seiner Fahrt von Bordeaux nach Bucuos-Ayres, an der Mündung des Rio de la Plata folgendes merkwiirdiges Phäuomen. Wăhrend auf dem Verdeck und in den uuteren Regionen der Masten eine voll- 